\title{
A rare case of uterus didelphys with full term pregnancy in left horn
}

\section{Tanvi Vijay Tuteja*, Kirti Rajesh Bendre, Geeta Niyogi}

Department of Obstetrics \& Gynecology, K.J Somaiya Medical College \& Research Centre, Mumbai, M.H., India

Received: 11 December 2014

Accepted: 23 December 2014

\section{*Correspondence:}

Dr. Tanvi Vijay Tuteja,

E-mail:dr_tanvi@yahoo.com

Copyright: (C) the author(s), publisher and licensee Medip Academy. This is an open-access article distributed under the terms of the Creative Commons Attribution Non-Commercial License, which permits unrestricted non-commercial use, distribution, and reproduction in any medium, provided the original work is properly cited.

\begin{abstract}
Uterus didelphys, also known as a duplicated uterus, is an embryological abnormality resulting from complete failure of fusion of Mullerian ducts causing full uterine development to erroneously occur bilaterally. It is associated with many obstetrical complications and thus has clinical importance. We present a case of an elderly patient with history of infertility diagnosed with uterus didelphys with a pregnancy in left horn. She carried pregnancy to term and delivered by caesarean section at 37 weeks of gestation. She had an uncomplicated intraoperative and postoperative period.
\end{abstract}

Keywords: Uterus didelphys, Mullerian ducts, Single pregnancy

\section{INTRODUCTION}

Uterus didelphys, also known as a duplicated uterus is an embryological abnormality that results from the failure of fusion of the Mullerian ducts, causing abnormal uterine development. The occurrence of uterus didelphys is very rare in general population and often predisposes women to variety of gynaecological problems. It can result in obstetrical complications such as spontaneous abortions, preterm labour, cervical incompetence and malpresentation. ${ }^{1,2}$

Uterus didelphys is associated with developmental urinary tract abnormalities. Pregnancy in a uterus didelphys is an uncommon; the incidence varies from 1 in 1500 to 1 in 142000 pregnancies worldwide. Although the true prevalence of congenital uterine anomalies in the population is unknown, it is known to vary from $0.1 \%$ to $10 \%{ }^{3}$ It comprises about $5-7 \%$ of all Mullerian anomalies. ${ }^{4}$ Pregnancies in a functional hemi-uterus originating from a single Mullerian duct (one horn of uterus didelphys, unicornuate unicollis) have a better prognosis with regard to the fetal wastage rate than a pregnancy in a uterus bicornuate, septate or arcuate. ${ }^{5}$

\section{CASE REPORT}

Mrs XYZ, a 35 years old primigravida presented to the Obstetric department with 3 months amenorrhea for routine antenatal check-up. She gave history of treatment for a tubo-ovarian mass on right for which she was given a full course of Anti-Koch's medications. She also gave history of infertility for 5 years. This pregnancy was a result of In Vitro Fertilisation.

Her vital parameters were normal. On per abdomen examination uterus was just palpable corresponding to around 12 weeks of pregnancy. On per speculum examination a complete vertical vaginal septum was seen. There were 2 separate cervix visualised on either side of vaginal septum (Figure 1). A per vaginal examination confirmed the presence of two cervices.

An obstetric ultrasound was performed which revealed two distinct widely separated uterine bodies with two separate cervices. A single viable 13 weeks pregnancy was seen in the left sided uterine body. The right uterine body revealed a reactionary endometrial thickening (Figure 2). 


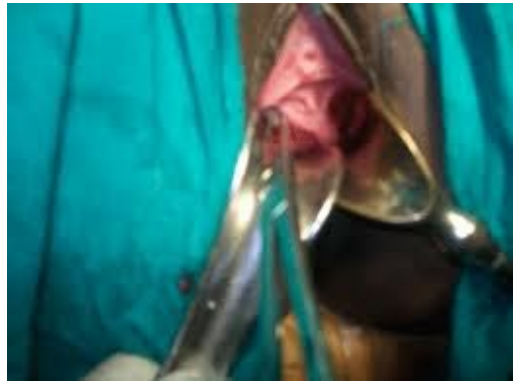

Figure 1: On per speculum examination - separate cervices were seen.

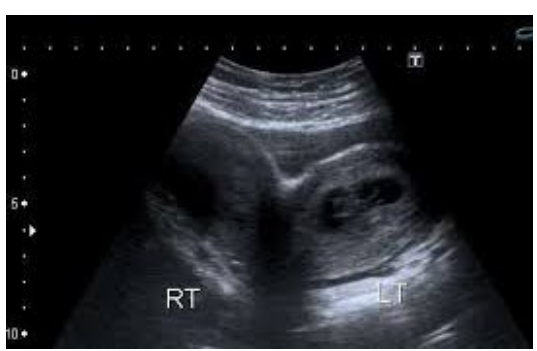

Figure 2: Ultrasound.

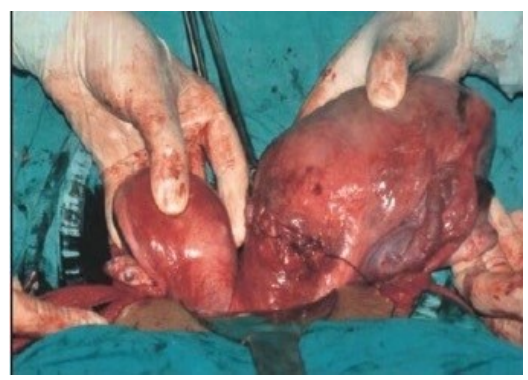

Figure 3: Intraoperative findings.

Patient was advised bed rest along with progesterone support. Regular antenatal check up with ultrasound were carried out. At 18 weeks of pregnancy a prophylactic cervical encirclage was done after a detailed anomaly scan. Pregnancy progressed well till term without any complications.

Ultrasound at term showed a full term pregnancy in cephalic presentation with adequate amniotic fluid and baby weight of approximately $3.2 \mathrm{~kg}$. She was posted for an elective lower segment caesarean section at 37 weeks of pregnancy in view of precious pregnancy. On opening the abdomen two separate horns of uterus and each ovary attached to each horn along with pregnancy in the left horn which was the dominant horn. Bilateral tubes and ovaries were normal (Figure 3). A lower segment incision was taken on the dominant horn and $3.3 \mathrm{~kg}$ baby was delivered uneventfully.
Uterine incision was sutured. Patient had an uneventful intra and post-operative period. Both mother and baby were discharged.

\section{DISCUSSION}

Congenital defects of the reproductive tract are often associated with great liability for preterm labour, abnormal presentations with dystocia and increasing necessity for caesarean section. Although pregnancy period may be uneventful, it is possible that uterine anomalies produce a considerable lower percentage of viable babies. The spontaneous abortion rates are estimated at $43 \%$, the premature birth rate is approximately $38 \%$ and the fetal survival rate is approximately $54 \%$ patients with uterus didelphys belong to a high risk group and deserve a particular prenatal care. Therefore it is of great importance for the clinical management of these cases that abnormalities of the reproductive tract are detected in early stage. Use of ultrasound especially 3D ultrasound is as reliable as laparoscopy or hysterosalpingography in these cases. ${ }^{6} \mathrm{~A}$ sensitivity of $97 \%$, specificity of $96 \%$ has been recorded for Mullerian anamolies. ${ }^{7}$ A $96 \%$ concordance between ultrasound and endoscopy with regards to type of anomaly had been documented.

Funding: No funding sources Conflict of interest: None declared

Ethical approval: Not required

\section{REFERENCES}

1. Heinonen PK. Uterus didelphys: a report of 26 cases. Eur J Obstet Gynecol Reprod Biol. 1984;17:345.

2. Cope HB, Sharp MC. Uterus didelphys, Am J Obstet Gynecol. 1954;67:172-5.

3. Decherney AH, Dlugi AM. Uterine factors in reproductive failure. Prog Obstet Gynecol. 1984;4:302.

4. Devi Wold Anne S, Norma Pham, Aydin Arici. Anatomic factors in recurrent pregnancy loss. Semin Reprod Med. 2006;24(1):25-32.

5. Green LK, Harris RE. Uterine anomalies; frequency of diagnosis and associated obstetric complications. Obstet Gynecol. 1976;47(4):427-9.

6. Mohamed M, Momtaz MD, Alaa N, Ebrashy MD, Ayman A, Marzouk MD. Three-dimensional ultrasonography in the evaluation of the uterine cavity. MEFS J. 2007;12:41-6.

7. Ghi T, Casadio P, Kuleva M, Perrone AM, Savelli L, Gianchi S, et al. Accuracy of three-dimensional ultrasound in diagnosis and classification of congenital uterine anomalies. Fertil Steril. 2009;92:808-13.

DOI: $10.5455 / 2320-1770 . i j \operatorname{rcog} 20150255$

Cite this article as: Tuteja TV, Bendre KR, Niyogi G. A rare case of uterus didelphys with full term pregnancy in left horn. Int J Reprod Contracept Obstet Gynecol 2015;4:275-6. 